\title{
ANALISIS HUBUNGAN INDEKS MASSA TUBUH (IMT) DAN LINGKAR ABDOMEN DENGAN TEKANAN DARAH PADA ORANG DEWASA DI DESA LANTIBUNG KABUPATEN BANGGAI LAUT
}

\author{
(Analysis Of Relationship Of Body Mass Index (BMI) And The Abdominal Girth With Blood \\ Pressure In Adults In The Village Lantibung Sea Banggai) \\ Nusrifa N. Mochtar ${ }^{1)}$, Kasman, Ph.D ${ }^{1)}$ \\ 1) Jurusan Fisika Fakultas Matematika dan Ilmu Pengetahuan Alam Unversitas Tadulako \\ Email:nusrifa49@gmail.com
}

\begin{abstract}
ABSTRAK
Telah dilakukan penelitian tentang analisis hubungan indeks massa tubuh (IMT) dan lingkar abdomen dengan tekanan darah pada orang dewasa di Desa Lantibung Kabupaten Banggai Laut. Penelitian ini bertujuan mengetahui hubungan antara indeks massa tubuh dan lingkar abdomen dengan tekanan darah pada masyarakat Desa Lantibung Kabupaten Banggai Laut. Data tinggi badan dan berat badan yang masing-masing diukur dengan stature meter dan alat timbangan berat badan untuk perhitungan IMT, sedangkan pengukuran lingkar abdomen dan tekanan darah masing-masing diukur menggunakan pita meteran dan sphygmomanometer untuk ditransformasikan kedalam risiko Cardiac Vasticuler Disease (CVD) dan kategori tekanan darah (TD). Pengolahan data dilakukan dengan menghitung nilai IMT, mengklasifikasikan kategori risiko Cardiac Vasticular Disease (CVD) dan kategori tekanan darah (TD), dan di uji dengan menggunakan uji chi kuadrat dan korelasi spearman. Berdasarkan uji statistik, terdapat hubungan antara IMT dengan tekanan darah dan terdapat hubungan antara lingkar abdomen dengan tekanan darah yang masing-masing mempunyai nilai korelasi sebesar $r=0,483$ dan $r=0,446$.
\end{abstract}

Kata kunci: Lingkar abdomen, IMT, tekanan darah, risiko CVD

\begin{abstract}
A research on the analysis of the relationship of body mass index (BMI) and abdominal circumference with blood pressure in adults in the village Lantibung Sea Banggai. This study aims to investigate the relationship between body mass index and abdominal circumference with blood pressure in the village community Lantibung Sea Banggai. Data height and weight are measured by stature meter and instrument weight scales for the calculation of BMI, while the measurement of abdominal circumference and blood pressure are measured using a tape measure and a sphygmomanometer to be transformed into the risk of cardiac Vasticuler Disease (CVD) and category Blood pressure (BP). Data processing is done by calculating the BMI value, to classify risk category Vasticular Cardiac Disease (CVD) and the category of blood pressure (BP), and tested using the chi square test and Spearman correlation. Based on statistical test, there is a relationship between blood pressure and BMI with the relationship between the circumference of the abdomen with blood pressure values each having a correlation of $r=0.483$ and $\mathrm{r}=0.446$.
\end{abstract}

Keyword: Abdominal circumference, BMI, blood pressure, risk of CVD. 


\section{PENDAhULUAN}

Tekanan darah merupakan faktor yang dapat dipakai sebagai indikator untuk menilai sistem kardiovaskular. Tekanan darah seseorang dipengaruhi oleh beberapa faktor di antaranya aktifitas fisik, massa tubuh, usia, zat makanan, riwayat keluarga, dan jenis kelamin (Marwadias, 2014). Selain faktor-faktor tersebut, menurut Sembulingan, PS. (2013), Ganong W. (2013), dan Majid A. (2005), ada sejumlah faktor yang dapat mempertahankan tekanan darah normal yang berkenaan dengan konsep fisika antara lain yaitu kecepatan aliran darah, tahanan tepi, volume darah, viskositas/ kekentalan darah, diameter pembuluh darah, dan elastisitas pembuluh darah. Dalam hal tersebut, kecepatan aliran darah berbanding terbalik dengan viskositas/ kekentalan darah dan tahanan aliran darah, hal ini dapat dilihat pada persamaan kontinutas $(\rho=$ konstan $)$.

$$
A_{1} v_{1}=A_{2} v_{2}
$$

Berdasarkan Persamaan 1, menunjukkan bahwa bila luas bidang penampang besar maka kecepatan aliran darah rendah, dan sebaliknya (Giancoli, 2014). Hal ini menunjukkan bahwa kecepatan aliran darah lebih cepat apabila terjadi penyempitan pembuluh darah yang bisa saja di akibatkan oleh meningkatnya viskositas/kekentalan darah dan meningkatnya tahanan terhadap aliran darah. Semakin kental darah yang melewati arteri maka semakin besar gesekan terhadap dinding pembuluh dan sebagai konsekuensinya diperoleh tekanan terhadap dinding arteri semakin besar (Samad, 2012).

Menurut Giancoli (2014), hubungan tekanan darah dan viskositas darah dapat diuraikan dengan persamaan Poiseuille berikut:

$$
Q=\frac{\pi\left(P_{1}-P_{2}\right) r^{4}}{8 \eta l}
$$

Berdasarkan Persamaan 2, laju aliran darah $Q$ berbanding lurus dengan gradient tekanan $\left(P_{1}-P_{2}\right)$, dan berbanding terbalik dengan panjang saluran $l$. Jika seseorang memiliki penimbunan kolesterol, maka jari-jari arteri $r$ akan mengecil sehingga akan mengakibatkan tekanan meningkat, dalam hal ini jantung akan bekerja lebih keras untuk mempertahankan laju aliran darah, namun biasanya tetap tidak dapat dipertahankan seperti semula. Kondisi ini dapat mengakibatkan tekanan darah meningkat. Begitu juga dengan elastisitas pembuluh darah yang dapat diregangkan dan 
dapat mempertahankan tekanan darah. ketika sifat elastis tersebut hilang, pembuluh darah akan menjadi kaku dan tekanan darah akan meningkat seperti terlihat pada usia lanjut.

Seseorang memiliki tekanan darah normal jika berkisar di bawah 120/80 $\mathrm{mmHg}$ dan menderita hipertensi jika melebihi 140/90 mmHg (Marwadias, dkk., 2014). Menurut Smeltzer dan Bare (2012), tekanan darah orang dewasa dapat diklasifikasikan seperti pada Tabel 1:

Tabel 1 Klasifikasi Tekanan Darah Dewasa

\begin{tabular}{|l|c|c|}
\hline $\begin{array}{c}\text { Klasifikasi } \\
\text { tekanan } \\
\text { darah }\end{array}$ & $\begin{array}{c}\text { Sistolik } \\
(\mathrm{mmHg})\end{array}$ & $\begin{array}{c}\text { Diastolik } \\
(\mathrm{mmHg})\end{array}$ \\
\hline Normal & $\leq 120$ & $\leq 80$ \\
\hline Prehipertensi & $121-139$ & $81-89$ \\
\hline Hipertensi & $\geq 140$ & $\geq 90$ \\
\hline
\end{tabular}

Sumber: (Smeltzer dan Bare, 2012)

Obesitas merupakan salah satu faktor penyebab naiknya tekanan darah. Orang yang mengalami obesitas biasanya pembuluh darahnya terjepit oleh kulit berlemak, sehingga jantungnya akan bekerja lebih cepat dalam memompa darah, sehingga mempengaruhi naiknya tekanan darah. Faktor obesitas dapat meningkatkan penyakit jantung koroner (PJK) dan menyebabkan kelainan metabolisme seperti naiknya tekanan darah dan kolesterol (WHO, 2010).

Selain itu, kelainan metabolisme dapat juga mempengaruhi jumlah lemak dalam tubuh/ kolesterol. Jumlah lemak dalam tubuh dapat diketahui dengan menggunakan persamaan indeks massa tubuh (IMT). IMT merupakan pengukuran yang dilakukan untuk menentukan jumlah lemak dalam tubuh dengan perbandingan antara berat badan (BB) dan kuadrat dari tinggi badan (TB), seperti di rumuskan pada Persamaan 3:

$$
I M T=\frac{B B(\mathrm{~kg})}{T B^{2}\left(\mathrm{~m}^{2}\right)}
$$

Penggunaan Persamaan 3 hanya untuk orang dewasa berusia di atas 18 tahun, dan tidak diterapkan pada bayi, remaja, ibu hamil, olahragawan, dan orang yang sakit (Supariasa, 2002).

Selain IMT, untuk menggambarkan jumlah lemak dalam tubuh dapat juga digunakan pengukuran lingkar abdomen (lingkar perut). Pengukuran lingkar abdomen merupakan metode yang digunakan untuk menentukan jumlah lemak pada intra abdominal (WHO, 2015). Tingginya nilai 
lingkar abdomen memiliki potensi terhadap penyakit jantung koroner (Cardiac Vasticuler Disease), yang dapat dikategorikan seperti Tabel 2.

Tabel 2 Kategori resiko CVD berdasarkan lingkar abdomen

\begin{tabular}{|l|c|c|}
\hline $\begin{array}{c}\text { Kategori } \\
\text { resiko CVD }\end{array}$ & Pria $(\mathrm{cm})$ & $\begin{array}{c}\text { Wanita } \\
(\mathrm{cm})\end{array}$ \\
\hline Sangat tinggi & $>120$ & $>110$ \\
\hline Tinggi & $100-120$ & $90-109$ \\
\hline Rendah & $80-99$ & $70-89$ \\
\hline Sangat rendah & $<80$ & $<70$ \\
\hline
\end{tabular}

Sumber: (International Diabetes Federation, 2006).

Sebelumnya telah dilakukan penelitian oleh Ardania dan Prabowo (2012), serta Mulyadi, dkk., (2014), yang menunjukkan bahwa IMT memiliki korelasi rendah terhadap tekanan darah dengan masing-masing korelasi sebesar $r=0,275$ dan $r=0,246$. Penelitian lain juga dilakukan oleh Sari, dkk., (2016) bahwa terdapat hubungan antara lingkar abdomen dan tekanan darah dengan kekuatan korelasi yang sedang yaitu $\mathrm{r}=$ 0,417 . Permasalahan tersebut mendasari peneliti untuk menganilisis hubungan antara indeks massa tubuh (IMT) dan lingkar abdomen dengan tekanan darah pada orang dewasa di Desa Lantibung, Kecamatan Bangkurung, Kabupaten Banggai Laut

\section{METODE PENELITIAN}

\section{Waktu dan Tempat Penelitian}

Penelitian ini dilakukan pada 21 Februari-9 Maret tahun 2019 di Desa Lantibung, Kecamatan Bangkurung, Kabupaten Banggai Laut.

\section{Alat dan Bahan}

Alat dan bahan yang digunakan pada penelitian ini yaitu Sphygmomanometer sebagai alat pengukur tekanan darah, stetoskop sebagai alat mendengarkan bunyi aliran darah pada arteri brachialis, Stature meter sebagai pengukur tinggi badan, pita meteran sebagai pengukur lingkar abdomen, timbangan berat badan sebagai pengukur berat badan responden, responden sebagai objek penelitian, dan program SPSS sebagai software untuk melihat hubungan antara IMT terhadap tekanan darah, dan hubungan antara lingkar abdomen terhadap tekanan darah.

\section{Pengolahan Data}

Langkah-langkah pengolahan data setelah dilakukan pengukuran yaitu menghitung nilai IMT untuk masing-masing reponden, dan mengelompokkan menjadi tiga kategori yaitu kurus-normal, overweight, dan obesitas. Data lingkar abdomen dikategorikan ke dalam kategori risiko CVD (Tabel 2), dan data tekanan darah 
dikategorikan sesuai dengan klasifikasi tekanan darah (TD) dewasa (Tabel 1) dengan masing-masing indeks massa tubuh. Selanjutnya menganalisis hubungan antara IMT dan tekanan darah, dan hubungan risiko CVD dan tekanan darah dengan menggunakan uji chi-kuadrat dan korelasi spearman.

Uji tersebut masing-masing menggunakan 2 hipotesis yaitu Hipotesis awal $\left(\mathrm{H}_{0}\right)$ yang tidak terdapat hubungan antara IMT dengan tekanan darah dan Hipotesisi alternatif $\left(\mathrm{H}_{\mathrm{a}}\right)$ yaitu terdapat hubungan antara lingkar abdomen dengan tekanan darah. Selanjutnya menentukan tingkat signifikan $(\sigma)$ yaitu sebesar 5\% atau 0,05. Melihat $\chi_{\text {tabel yang }}^{2}$ diperoleh dari tabel statistik $\chi^{2}$ dengan cara melihat nilai $\mathrm{p}=0,05$ dan nilai derajat kebebasan ( $\mathrm{df}=\mathrm{K}-1)$. Kriteria pengujian: jika $\chi_{\text {hitung }}^{2}>\chi_{\text {tabel }}^{2}$, atau nilai $\mathrm{p}(\mathrm{sig})<0,05$ maka $\mathrm{H}_{0}$ ditolak. Jika $\chi^{2}{ }_{\text {hitung }}<\chi^{2}$ tabel, atau $\mathrm{p}$ (sig) > 0,05 maka $\mathrm{H}_{0}$ diterima. Hipotesis untuk korelasi spearman sama dengan hipotesis untuk uji chi-kuadrat, dengan nilai sig. (2-tailed) $<0,05$ maka $\mathrm{H}_{0}$ ditolak atau $\mathrm{H}_{\mathrm{a}}$ diterima. Untuk lebih mengetahui besar koefisien korelasi, berikut adalah interpretasi koefisien korelasi yang dapat digunakan.
Tabel 3 Interpretasi Koefisien Korelasi Nilai

\begin{tabular}{|c|c|}
\hline $\begin{array}{c}\text { Interpretasi } \\
\text { Koefisien Korelasi }\end{array}$ & $\begin{array}{c}\text { Interpretasi } \\
\text { Hubungan }\end{array}$ \\
\hline $0,80-1,000$ & Sangat kuat \\
\hline $0,60-0,799$ & Kuat \\
\hline $0,40-0,599$ & Sedang \\
\hline $0,20-0,399$ & Rendah \\
\hline $0,00-0,199$ & Sangat rendah \\
\hline
\end{tabular}

Sumber : Sugiyono (2010).

\section{HASIL DAN PEMBAHASAN}

Data yang diperoleh dalam penelitian ini berjumlah 90 responden dari populasi sebanyak 668 orang berusia 18-50 tahun dengan kategori IMT kurus-normal, overweight serta obesitas. Data tersebut kemudian di distribusikan ke kategori IMT, CVD, dan TD terhadap usia responden yang masing-msaing dapat dilihat pada Gambar 1, Gambar 2, dan Gambar 3.

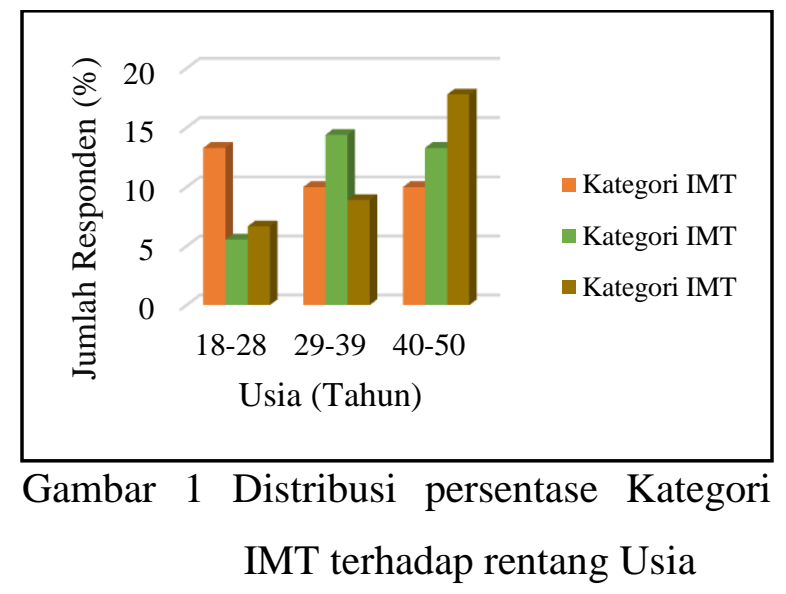


Gambar 1 menunjukkan bahwa dengan bertambahnya usia, jumlah responden dengan kategori IMT kurus-normal menurun, sedangkan kategori obesitas meningkat, dan kategori IMT overweight cenderung naik. Hal ini disebabkan karena dengan bertambahnya usia, kemampuan metabolisme lemak dalam tubuh menurun dan tidak seimbang dengan pola makan dan aktifitas olahraga, sehingga banyak lemak yang tertimbun di intra abdominal, seperti yang di ungkap oleh Hidayati dkk., (2010) bahwa pola makan yang tidak teratur dan tidak di imbangi oleh aktifitas fisik dapat menimbulkan kelebihan berat badan.

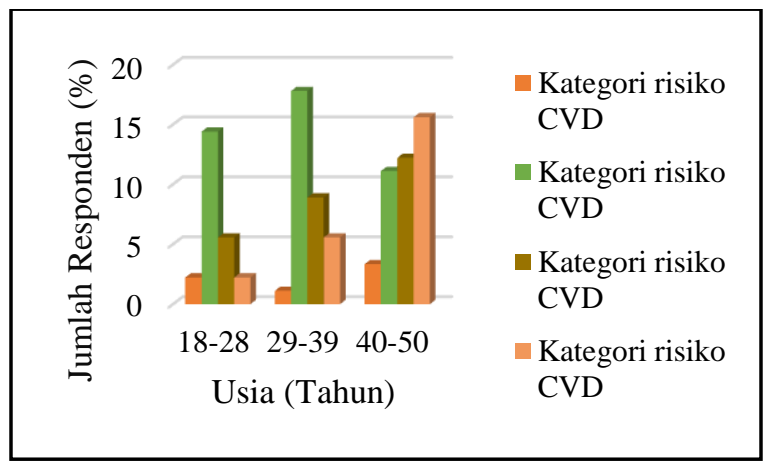

Gambar 2 Distribusi persentase Kategori CVD terhadap rentang Usia

Gambar 2 menunjukkan bahwa pada usia 18-28 tahun dan usia 29-39 tahun, jumlah persentase terbanyak terdapat pada kategori CVD rendah yang masing-masing sebesar $14,4 \%$ dan $17,8 \%$, sedangkan untuk usia $40-$
50 tahun jumlah persentase terbanyak terdapat pada kategori CVD sangat tinggi yaitu 15,6\%. Hal ini disebabkan karena pada usia tersebut dapat dikatakan bahwa lingkar perut tertimbun lebih banyak lemak pada intra abdominal yang dipengaruhi oleh kurangnya aktifitas fisik dan metabolisme tubuh menurun (Muchtadi, 2001).

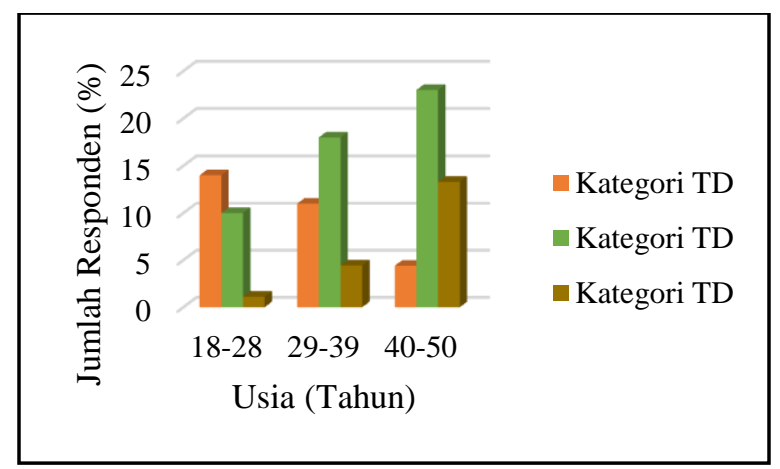

Gambar 3 Distribusi persentase Kategori TD terhadap rentang Usia

Gambar 3 menunjukkan bahwa dengan bertambahnya usia, jumlah responden dengan kategori tekanan darah prehipertensi dan hipertensi meningkat, sebaliknya kategori tekanan darah normal menurun. Hal ini terjadi karena pengaruh elastisitas pembuluh darah, seperti yang di ungkap oleh Sembulingan (2013), Ganong (2013), dan Majid (2005), seiring dengan bertambahnya usia tekanan darah akan meningkat karena kurangnya elastisitas pembuluh darah. 
Hubungan kategori IMT dengan tekanan darah (TD) dan kategori CVD dengan TD dapat diketahui dengan menggunakan uji chi-kuadrat dan korelasi spearman. Hasil uji statistik tersebut dapat dilihat pada Tabel 4 dan Tabel 5.

Tabel 4 Hubungan kategori IMT dan TD

\begin{tabular}{|c|c|c|c|c|c|}
\hline \multirow{2}{*}{$\begin{array}{c}\text { Kategori } \\
\text { IMT }\end{array}$} & \multicolumn{3}{|c|}{ Kategori TD } & \multirow[b]{2}{*}{$X^{2}$} & \multirow[b]{2}{*}{$\mathrm{r}$} \\
\hline & $\mathrm{N}$ & $\begin{array}{l}\text { Pre- } \\
\text { Hiper }\end{array}$ & Hiper & & \\
\hline $\mathrm{KN}$ & $\begin{array}{c}22 \\
(24,4 \\
\%)\end{array}$ & $\begin{array}{c}6 \\
(6,7 \%)\end{array}$ & $\begin{array}{c}2 \\
(2,2 \\
\%)\end{array}$ & \multirow{3}{*}{$\begin{array}{c}45,33 \\
3\end{array}$} & \multirow{3}{*}{$\begin{array}{c}0,48 \\
3\end{array}$} \\
\hline Ow & $\begin{array}{c}9 \\
(10 \%)\end{array}$ & $\begin{array}{c}17 \\
(18,9 \\
\%)\end{array}$ & $\begin{array}{c}4 \\
(4,4 \\
\%)\end{array}$ & & \\
\hline $\mathrm{O}$ & $\begin{array}{c}7 \\
(7,8 \%)\end{array}$ & $\begin{array}{c}12 \\
(13,3 \\
\%)\end{array}$ & $\begin{array}{c}11 \\
(12,2 \\
)\end{array}$ & & \\
\hline
\end{tabular}

Berdasarkan Tabel 4 diperoleh nilai $\mathrm{X}^{2}=$ 45,333 dan $\mathrm{r}=0,483$ dengan nilai $\mathrm{p}($ sig. $)<$ 0,05. Hal ini menunjukkan bahwa terdapat hubungan antara IMT (indeks massa tubuh) dengan TD (tekanan darah) dengan korelasi sedang.

Tabel 5 Hubungan kategori CVD dan TD

\begin{tabular}{|c|c|c|c|c|c|}
\hline \multirow{2}{*}{$\begin{array}{c}\text { Kategori } \\
\text { CVD }\end{array}$} & \multicolumn{3}{|c|}{ Kategori TD } & \multirow[b]{2}{*}{$X^{2}$} & \multirow[b]{2}{*}{$r$} \\
\hline & $\mathrm{N}$ & $\begin{array}{c}\text { Pre- } \\
\text { Hiper }\end{array}$ & Hiper & & \\
\hline SR & $\begin{array}{c}3 \\
(3,3 \%)\end{array}$ & $\begin{array}{c}3 \\
(3,3 \%)\end{array}$ & 0 & \multirow{4}{*}{$\begin{array}{c}74,37 \\
8\end{array}$} & \multirow{4}{*}{$\begin{array}{c}0,44 \\
6\end{array}$} \\
\hline $\mathrm{R}$ & $\begin{array}{c}25 \\
(27,8 \\
\%)\end{array}$ & $\begin{array}{c}11 \\
(12,2 \\
\%)\end{array}$ & $\begin{array}{c}3 \\
(3,3 \\
\%)\end{array}$ & & \\
\hline $\mathrm{T}$ & $\begin{array}{c}6 \\
(6,7 \%)\end{array}$ & $\begin{array}{c}11 \\
(12,2 \\
\%)\end{array}$ & $\begin{array}{c}7 \\
(7,8 \\
\%)\end{array}$ & & \\
\hline ST & $\begin{array}{c}4 \\
(4,4 \%)\end{array}$ & $\begin{array}{c}10 \\
(11,1 \\
\%)\end{array}$ & $\begin{array}{c}7 \\
(7,8 \\
\%)\end{array}$ & & \\
\hline
\end{tabular}

Berdasarkan Tabel 5 diperoleh nilai $\mathrm{X}^{2}=$ 74,378 dan $r=0,446$ dengan $p($ sig.) $<0,05$. Hal ini menunjukkan bahwa terdapat hubungan antara lingkar abdomen dan tekanan darah dengan korelasi sedang.

\section{IV.KESIMPULAN}

Berdasarkan hasil uji statistik diperoleh hubungan antara IMT terhadap tekanan darah, dan terdapat hubungan antara lingkar abdomen terhadap tekanan darah dengan masing-masing nilai korelasi sedang yaitu $r=0,483$ dan $r=$ 0,446 .

\section{DAFTAR PUSTAKA}

Ardania, S., dan Prabowo T., (2012). Hubungan Indeks Massa Tubuh dengan Tekanan Darah pada Masyarakat Di Kelurahan Pakuncen Wirabrajan Yogyakarta. Yogyakarta: STIKES 'AISYIYAH.Ganong W., (2013). Textbook Of Medical Physiologi. 24th ed. Newyork: McGraw Hill.

Giancoli, D.C., (2014). Fisika Prinsip dan Aplikasi Edisi Ketujuh Jilid 1. Jakarta: Erlangga.

Hidayati L., Juliani P., dan Zahara A.M., (2010). Ragam Jajanan Anak dan Kontribusi Jajanan Terhadap Kecukupan Energi dan Zat Gizi Anak Malnutrisi di Lingkungan Kumuh Perkotaan. Surakarta: UMS. 
International Diabetes Federation, (2006). Diagnosing Diabetes and Learning About Prediabetes.

Majid A., (2005). Fisiologi Kardiovaskular. Medan: Bagian Fisiologi Fakultas Kedokteran Universitas Sumatra Utara.

Marwadias, N., Susilani, A., dan Ratnaningsih, D., (2014). Hubungan Indeks Massa Tubuh dan Lingkar Pinggang Dengan Tekanan Darah Pada Wanita Dewasa Di Dusun Kalibang Desa Wonokerto Kecamatan Wonogiri Kabupaten Wonogiri Provinsi Jawa Tengah Tahun 2014. JPI: Volume 5, Nomor 2.

Muchtadi, D., (2001). Pangan dan Gizi, Pencegahan Gizi Lebih dan Penyakit Kronis Melalui Perbaikan Pola Konsumsi Pangan. Penerbit: Sagung Seto: Institut Pertanian Bogor. Hal: 94-103.

Samad, S. (2012). Analisis kecepatan Darah Pada Aorta Abdominalis Bagi Pasien Hipertensi Dengan Mengunakan Color Doppler Sonografi. Fisika FMIPA, UNHAS. Makassar.

Sari, M.K., Lipoedo, N.I., dan Herman, R.B., (2016). Hubungan Lingkar Abdomen dengan Tekanan Darah. Jurnal Kesehatan Andalas; 5(2).

Sembulingan PS., (2013). Fisiologi Kedokteran. 5th ed. Pamulangi: Binarupa Aksara.

Smeltzer \& Bare, (2012). Buku Ajar Keperawatn Medikal Bedah, Edisi 4 Volume 2, Jakarta: EGC.
Sugiyono. (2010). Metode Penelitian Bisnis. Alfabeta. Bandung.

Supariasa Nyoman. (2012). Penilaian Status Gizi. Jakarta : Penerbit Buku Kedokteran EGC.

World Health Organization. The problem of overweight and obesity. WHO Media Centre; 2010.

World Health Organization. The problem of overweight and obesity. WHO Media Centre; 2015. 